\title{
Characteristics of Policies Regarding the State Financial Accountability Agency the House of Representatives of the Republic of Indonesia
}

\author{
A. Junaidi Auly ${ }^{1}$, Bahrullah Akbar ${ }^{2}$, Didik Suhardi ${ }^{3}$, Nirva Diana ${ }^{4}$ \\ 1,2,3,4 Institut Pemerintahan Dalam Negeri, Indonesia \\ Email: junaidi.auly@gmail.com
}

\begin{abstract}
This study explains the characteristics of the policies of the State Financial Accountability Board of the People's Representative Council of the Republic of Indonesia, from now on referred to as BAKN. The research method in this research uses qualitative methods. A qualitative approach is used because of the method's relevance to research themes related to accountability state finances Accountability. The theory used is the theory of implementation proposed by Mazmanian and Sabatier. The research findings show that from the policy characteristics, the MD3 policy by BAKN still does not have clarity and consistency, including the continued existence of BAKN, which could have been dissolved as in the previous year. This policy still does not fulfill the causal theory in which the policy as a basis always does not comply with the substance of the purpose of the establishment of BAKN.
\end{abstract}

Keywords: Policy Characteristics, State Finance, State Financial Accountability Agency.

\section{A. INTRODUCTION}

International financial institutions were very interested in promoting greater transparency in public financial management following the Asian financial crisis in the late 1990s, even though this crisis has exposed the structural weaknesses of financial information systems in developing countries (Santiso \& Belgrano, 2004). Alternative steps that can be taken are increasing the legislative contribution to budget oversight, which is increasingly seen as a way to strengthen government accountability and reduce corruption in operationalizing public financial management (OECD, 2002).

The first wave of reforms in public financial management in the late 1980s and early 1990s has focused on improving public financial administration and promoting greater transparency and efficiency in general financial management (Dorotinsky, 2002). During the 1990s, most Latin American countries made significant efforts to improve their public financial management and information systems (Dorotinsky, 2002). However, there is still a lack of attention paid to the simultaneous need to strengthen Accountability, control, and integrity mechanisms in budget management. Peru's experience in the 1990s clearly shows the limits of rapid decision making and consequently, the need to strengthen accountability mechanisms.

Legislative oversight refers to the legislative review and evaluation of the executive branch of government's selected activities. In contrast, the legislative 
branch carries out supervisory activities because it not only has the power to create new programs for the country but also must ensure that existing programs are implemented and managed efficiently, effectively. And in a manner consistent with legislative aims/objectives (Anderson, 2009). While oversight is one of the legislature's main focuses, it is an integral part of the legislative process, which is often difficult to separate from the law-making process. On the other hand, it is clear that oversight is the focus of some elected members, and special oversight committees can also be part of hearings and committee work (Stair-Hall, 2011).

Efforts to create Accountability for state finances continue to be made by various parliamentary institutions, one of which is carried out by the Indonesian parliament through the House of Representatives (DPR). The DPR is a state institution in the Indonesian constitutional system, a representative institution for the people. The DPR consists of political parties participating in general elections who are elected through simultaneous general elections. In the context of supervision, the DPR has a supervisory function through oversight of the Implementation of the Law and APBN.

DPR oversight of state finances starts from the budget preparation stage following Article 23 of the 1945 Constitution of the Republic of Indonesia and Article 15 of Law Number 17 of 2003 concerning State Finances. However, the supervision of the Accountability and Accountability of state finances is carried out by the DPR after the Supreme Audit Agency of the Republic of Indonesia (BPK) submits a report on the results of the state financial audit to the DPR following Article 17 of Law Number 15 of 2006 concerning the Supreme Audit Agency.

Efforts to improve the oversight function of the DPR on the Accountability of state finances, based on the provisions of Law Number 27 of 2009 concerning the People's Consultative Assembly, the People's Representative Council, the Regional Representative Council, and the Regional People's Representative Council (which is better known as the MD3 Law), particularly in Article 110, it is stipulated that the State Financial Accountability Body, from now on abbreviated as BAKN, is formed by the DPR RI and is a permanent body of the DPR-RI.

Based on the provisions of Law Number 27 of 2009 concerning MD3 and DPR-RI Regulation Number 01 of 2010 concerning Rules, in particular, Article 70, Article 71, and Article 72, the scope of duties of BAKN is determined, including for; (1) Reviewing the findings of the examination by the Supreme Audit Agency of the Republic of Indonesia (BPK-RI) submitted to the DPR-RI, (2) Submitting the results of the review by BAKN to the Commissions in the DPR-RI, (3) Taking action -follow up the results of the commission's discussion on the findings of the BPK-RI examination at the commission's request, and (4) Provide input to the BPK-RI in terms of annual audit work plans, audit barriers, and report presentation and quality. The results of BAKN's work are then conveyed to the DPR Leadership through regular plenary meetings.

In its journey, BAKN also does not necessarily increase the active and passive supervision of state finances; various problems have been experienced. These 
problems include: relating to the tractability of the problem, the ability of the statute to structure the implementation process favorably, and non-statutory variables affecting Implementation (Bardach, 1977). Based on this, the researcher tries to explore and research these problems and try to describe the policy characteristics that exist in the State Financial Accountability Agency (BAKN).

\section{B. METHOD}

The approach that has been used in this research is descriptive analysis with a qualitative approach. The qualitative approach is based on the formulation of symptoms, information, or statements regarding the policy characteristics of the People's Consultative Assembly, the People's Representative Council, the Regional Representative Council, and the Regional People's Representative Council by the State Financial Accountability Agency. Thus, in this study, the researcher describes a reality regarding the People's Consultative Assembly's policy characteristics, the People's Representative Council, the Regional Representative Council, and the Regional People's Representative Council by the State Financial Accountability Agency. Based on this, the most appropriate type of research is the qualitative type with the descriptive analysis method, where data and analysis are more in the form of words (Cresswell, 2010).

\section{RESULT AND DISCUSSION}

\section{Policy Implementation Model at BAKN}

Mazmanian, Daniel \& Sabatier (1983), explain that implementation is the carrying out of a basic policy decision, usually incorporated in a statute but can also take the form of import executive orders or court decisions. Ideally, that decision identifies the problem to be addressed, stipulates the objective to be pursued, and "Structures" the implementation process in various ways.

Based on this opinion, it can be seen that implementation is the implementation of fundamental policy decisions, usually included in the law, but which can also be in the form of imports from executive orders or court decisions. Ideally, the decision identifies the problems to be addressed, sets the objectives to be pursued, and in various ways and structures the implementation process. As for policy implementation research, there are multiple theories and models of policy implementation.

The implementation model in this study refers to the theory of Mazmanian, Daniel \& Sabatier. This theory results from an abstract systems model that is not easily operationalized and because it does not identify which variables are controlled by various actors (Sabatier \& Mazmanian, 1980). The work of Sabatier \& Mazmanian (1980) serves to develop the top-down model further. The authors presented 17 variables in three categories (problem tractability, ability to apply statutes to structures, and non-legal variables affecting implementation) that they thought influenced the probability of successful implementation. This model's salient feature is that the authors focus on "legal and political mechanisms for 
affecting the preferences and constraining the behavior of street-level bureaucrats" (Sabatier, 1986). Sabatier and Mazmanian argue that it is possible to keep street-level bureaucrats' behavior within acceptable limits over time if conditions are met.

In general, top-downers aim to develop generalizable policy advice for policymakers. General top-down advice includes the following prescriptions: (1) make policy goals clear and consistent; (2) minimizing the number of policy actors; (3) limiting the rate of change required; and (4) placing implementation responsibilities with agencies sympathetic to policy objectives (Matland, 1995).

\section{Policy Characteristics}

a. Clarity of Consistency of Purpose

Mazmanian, Daniel \& Sabatier (1983) explain that "Legal objectives which are precise and ranked in importance serve as an indispensable aid in program evaluation, as unambiguous directives to implement officials and as a resource to supporters of those objectives". Based on this definition, it is explained that consistent and transparent policy objectives are important and serve as indispensable assistance in evaluating policy programs, as clear directions for implementing officials, and as a resource to support these policy objectives.

Official objectives that are carefully formulated and laid out in order of importance play a vital role as a tool in policy implementation, as concrete guidelines for executing officials, and as a source of support for that end. Clear objectives can also act as sources for the actors involved, both within the institution and those outside the institution. The more capable a regulation is to provide accurate and structured instructions in order of importance to executing officials and other actors, the more likely it is that the policy outputs of implementing agencies and the behavior of target groups will, in turn, be consistent with these directives the hint.

An MD3 policy taken by a policymaker must contain clear and consistent content in the context of Accountability. MD3 policies related to BAKN with precise content will facilitate policies and avoid distortions or deviations in their implementation. This is because if an MD3 policy related to BAKN already has clear content, then the possibility of misinterpretation by the implementors will be avoided and vice versa; if the contents of policy are still unclear or floating, the potential for distortion or misunderstanding will be large.

The findings show that the task change in MD3 did not undergo much difference, only related to requests for discussion by a different commission. As such, the operationalization and policies carried out by BAKN did not experience any significant changes as a rule. It's just that improvements to the work system are continuously being improved so that BAKN has standard work standards. Based on this, it is clear that BAKN has no clarity in clear standard operational standards. On this side, it is strengthened by the observation where there is no clear reference regarding the review of the results of the examination conducted by BAKN. 
In the context of consistency, researchers in Accountability, especially the policy portrait, have not yet been developed. This is reinforced in a documentation study where the regulations related to BAKN have changed from the previous year. On this side, it is clear that there is no meaningful consistency in policies regarding BAKN. The findings show that political parties urgently support the consistency of BAKN through the factions in the DPR RI. However, when the urgency fades, BAKN can be dissolved again as it was in the past.

Based on the study results, it can be concluded that there is a lack of clarity in the work standards of BAKN, mainly which focus is the BAKN's attention in its analysis. There is no annual map, which implies an abstract and erratic analysis. On the other hand, policies related to BAKN have not yet been formed, especially on the consistency of factions in the DPR in defending BAKN. BAKN may be dissolved when there is a revision in MD3.

b. Adequate Use of Causal Theory

Mazmanian, Daniel \& Sabatier (1983) explain that every reform contains at least implicity a causal theory of how its objectives are to be attained. One of the significant contributions of implementation analysis instead of merely public administration and organization theory is its emphasis on the overall theory for obtaining desired changes. Based on this definition, it is explained that every reform contains at least implicitly a causal theory of the way it is achieved. Theoretical support will make a rule or policy more reliable because, of course, it has been tested. However, because the context in policymaking is related to financial Accountability, although in general, it looks the same in every institution, some things are a little different so that to overcome this, modifications can be made. In this concept, policies that have a theoretical basis have a more stable character because they have been tested, although, for specific social environments, it is necessary to modify them.

The findings show that following the MD3 Law, BAKN's task is to review the results of BPK audits of ministries/institutions that are partners of the commission in the DPR RI. The results of BAKN's review are then submitted to the relevant commission for follow-up. In general, the regulations related to BAKN are sufficient in implementing the duties of BAKN. However, revising the MD3 Law, such as those related to authority and membership, may still be needed. What is required is the strengthening of experts in assisting the review process of the BPK examination results. Based on these findings, it is clear that the MD3 law has not shown theoretic suitability of the importance of Accountability.

In the theoretical context, public Accountability has a vast scope, including reporting on public resources. In public Accountability, it is necessary to report to resource providers. According to Caiden (in Bahrullah and Achmad, 2015), "To be accountable is to answer for one's responsibilities, report, explain, give a reason, respond, and assume obligations to render a reckoning and to submit to outside or external judgment". To be accountable, the organization must carry out reporting activities, providing explanations, reasons, and responses that also consider external 
conditions. According to Kluvers (in Bahrullah \& Achmad, 2015), accountability in the public sector is different from that of the private sector. It involves complex multifaceted relationships, many roles and tasks with differing risks, uncertainties, and diverse and often conflicting expectations.

Based on the study results, it can be concluded that in principle, the existence of BAKN has adequate theoretical relevance, especially regarding the importance of Accountability in the public sector. Implementing the MD3 policy regarding BAKN has a clear casual relationship in the framework of building public Accountability in each institution. Problems occur when these theories have not been summarized in a comprehensive MD3 policy, especially on the determination of authority and quantity of BAKN membership.

c. Accuracy of Fund Source Allocation

Based on Mazmanian, Daniel \& Sabatier (1983), money is critical in any social services program. It is also required in classical regulatory programs to hire the staff and conduct the technical analyzes involved in developing regulations, the administration of permit programs, and monitoring compliance. In general, a threshold level of funding is necessary if there is to be any possibility of achieving statutory objectives, and the level of funding above this threshold is (up to some saturation point) proportional to the probability of achieving those objectives. Based on this explanation, it can be seen that the budget is essential in any accountability policy. In classical regulatory programs, it is also required to hire staff and carry out technical analysis involved in regulatory development, permit administration, and compliance monitoring. In general, a threshold level of funding is required if it is possible to achieve a legal objective. A level of the financing above this threshold (to some point of saturation) is proportional to the likelihood of achieving that objective.

From the aspect of the appropriateness of the allocation of sources of funds, it can be seen that funds are undeniably one of the determining factors in the financial accountability program. In regulative programs, funds are also required to pay or hire labor and enable the technical analysis needed to make these rules/regulations. In general, the availability of funds is very much required so that there will be opportunities to achieve the BAKN accountability program's formal objectives. Furthermore, financial resources are a crucial factor for any operationalization of BAKN. Each program also requires staff support to perform administrative and technical work, and program monitoring, all of which come at a cost.

The results showed that the budget for BAKN was sufficient because it was related to the number of members, so it was adjusted according to the need for meetings, consultations, RDP / U, or work visits. If there is no reduction, the current budget allocation is enough, but if needed, an additional budget can still propose additional budget support for the DPR.

Based on the research results, it can be concluded that in the budget context, BAKN has sufficient availability where the budget can cover the various needs of members in carrying out their duties. Even on a particular side, the budget can be added if this is urgent to optimize BAKN. 
d. Integrated Hierarchy within and Between Implementing Agencies

Based on Mazmanian, Daniel \& Sabatier (1983), explain that one of the bestdocument findings in implementation literature is the difficulty of obtaining coordinated action within any given agency and among the numerous semiautonomous agencies involved in most implementation efforts. Based on the explanation above, it can be seen that one of the best findings from implementation is the difficulty in obtaining coordinated action within each particular agency and among the various semi-autonomous institutions involved in the implementation effort. In this concept, one of the essential features that any good statutory regulation needs to have is its ability to integrate the hierarchy of implementing agencies, when the knowledge to unify agencies, agencies, and institutions, coordination between agencies aimed at facilitating the implementation of policies will destroy the objectives of the policies that have been set.

The findings show that BPK RI, as the leading partner of BAKN, is very supportive and provides the data needed by BAKN. In fact, with the existence of BAKN, the output of BPK audits can be followed up by the DPR, one of which is through BAKN. The BPK is very helpful in terms of the needs of BAKN's studies and activities. Meanwhile, internal integration related to the BAKN secretariat is coherent in that the BAKN secretariat is very supportive of various BAKN programs in the framework of BAKN work meetings or work visits.

Problems arise related to integration in the framework of commitment in carrying out recommendations. In every study, even during a working visit, sometimes there is an appeal for the importance of implementing the recommendations of BAKN and BPK. Still, based on observations, it has not been seen that each implementing agency's cohesiveness to carry out recommendations in the results of the examination actively.

Based on the research results, it can be seen that the integration has been built between the BPK and BAKN; even in the internal scope of the secretariat, it also appears in various BAKN activities in carrying out tasks as mandated by MD3.

e. Integrated Hierarchy within and Between Implementing Agencies

Mazmanian, Daniel \& Sabatier (1979) explain that in addition to providing clear and consistent objectives, few veto points, and adequate incentives for compliance, a statute can further bias the implementation process by stipulating the formal decision rules of the implementing agencies. Based on this opinion, it can be seen that in addition to providing clear and consistent objectives, several decision points, and adequate incentives for compliance, laws can further bias the implementation process by establishing formal decision rules from the implementing agency. On this side, a consistent decision on Accountability becomes a reference for how policy implementation can run effectively. The law can also give the authority to make final decisions in the implementing agency to those officials who are most likely to support mandatory objectives. Finally, when a multi-member commission is involved, the law can establish the majority required for specific actions. 


\section{f. Recruitment of Implementing Officers}

Mazmanian, Daniel \& Sabatier (1979) explain that no matter how well a statute structures the formal decision process, the attainment of statutory objectives which seek to modify target group behavior significantly is unlikely unless officials in the implementing agencies are strongly committed to the achievement of those objectives.

Based on this opinion, it can be seen that in formulating policies related to reviews, it is essential for BAKN members to build memberships that support the Implementation of MD3. No matter how well the law constitutes a formal decision process, achieving the goal of a law that seeks to significantly change target groups' behavior is unlikely unless officials in the implementing agency are deeply committed to the achievement of those goals.

The research findings show that BAKN membership is not automatically chosen based on competence or ability. BAKN membership can be selected depending on the internal decision of who will be assigned to BAKN. An interesting finding was when most BAKN members were placed in Commission XI, which was in partnership with the Secretary-General of the BPK. On this side, there will indeed be a strengthening of efforts to synergize discussions. Still, it is essential to consider other commissions, which are the urgency of being given equal rights in building Accountability.

Based on the results of the analysis, it can be seen that the MD3 regulation is only based on the number of members in BAKN; it does not explain the competency obligations related to Accountability, which, if applied, will undoubtedly make it easier to operationalize BAKN's duties and functions. It is not surprising that BAKN still focuses on Commission XI issues, where most BAKN is assigned, Commission XI.

g. Integrated Hierarchy within and Between Implementing Agencies

Based on Mazmanian, Daniel \& Sabatier (1983) explain that another factor affecting implementation is the extent to which opportunities for participation by actors outside the implementing agencies are biased toward supporters of legal objectives. Based on this explanation, it can be seen that another factor affecting implementation is the extent to which opportunities for participation by actors outside the implementing agency are inclined towards supporting legal objectives. Furthermore, it can be seen that another factor that can influence policy implementation is the extent to which opportunities for participation are open to actors outside the implementing agencies to control the supporters of the objectives. Actors outside the implementing agency who are willing and able to support the program can influence the achievement of goals.

Community participation is a form of community participation or involvement in development programs. This community participation shows that the community feels involved and feels part of development. This will have a very positive impact on the successful implementation of a program. Increasing public participation, both qualitatively and quantitatively, manifests these changes in 
attitudes and behavior. The pattern of involvement is the active participation of community members at various levels of activity. Viewed from the context of accountability policies, participation is community involvement, manifested in forging partnerships between multiple activities.

On this side, it can be seen that the extent of access for external groups to participate in the Implementation of MD3 policies can be found in the easy access for outsiders to access BAKN information. However, based on the research results, access to external parties has not yet been developed where BAKN programs only refer to obtaining access to accountability data, not finally showing data on work results to other parties, in this case, the community NGOs. Of course, this finding is unfortunate when a program that provides broad community involvement opportunities will get relatively support from a program that does not involve the community. People will feel isolated or alienated if they only become spectators of programs in their area.

Based on these results, it can be concluded that formal access is still normative, activities are still local. The point is that access is only to specific focuses, which is also discussed at open BAKN meetings. The context of Accountability is not only on that side; BAKN needs to establish the broadest possible public openness to provide feedback on the public's performance, which has not been developed so far.

\section{CONCLUSION}

Judging from the policy's characteristics, the MD3 policy by BAKN still does not have clarity and consistency, including the continuation of BAKN, which could have been dissolved as in the previous year. This policy still does not fulfill the causal theory in which the policy as a basis always does not comply with the substance of the purpose of the establishment of BAKN. It is not surprising that BAKN recommendations in every meeting and working visit are not binding; this has led to neglect in implementing agencies' relationship. Not to mention the issue of limited formal access by outsiders and recruitment only explaining a maximum of 1 faction, not explaining competency requirements, especially in audits, which are identical to the needs of BAKN. BAKN is supported by a large funding source, which can be seen from the budget support for the Implementation of BAKN's tasks.

\section{REFERENCES}

1. Anderson, B. (2009). The changing role of parliament in the budget process. OECD Journal on Budgeting, 9(1), 1-11.

2. Bardach, E. (1977). The implementation game. Mit Press.

3. Creswell, J. W. (2010). Research Design Pendekatan Kualitatif, Kuantitatif, dan Mixed. Yogyakarta: Pustaka Pelajar.

4. Dorotinsky, W. (2002). Reforma de la gestión financiera en América Latina: Una perspectiva institucional. Revista del CLAD Reforma y Democracia, (23).

5. Dye, T. R., \& Dye, T. R. (1992). Understanding public policy. Englewood Cliffs, NJ: Prentice-Hall. 
6. Giacchino, S., \& Kakabadse, A. (2003). Successful policy implementation: the route to building a self-confident government. International Review of Administrative Sciences, 69(2), 139-160.

7. Hargrove, E. C. (1975). The missing link: The study of the implementation of social policy (Vol. 797, No. 1). Urban Inst Pr.

8. Khan, A. R. (2016). Policy implementation: Some aspects and issues. Journal of Community Positive Practices, 3, 3-12.

9. Law Number 15 of 2006 concerning the Supreme Audit Agency.

10. Law Number 27 of 2009 concerning the People's Consultative Assembly, the People's Representative Council, the Regional Representative Council, and the Regional People's Representative Council

11. Mazmanian, D. A., \& Sabatier, P. A. (1983). Implementation and Public Policy. Scott Foresman.

12. OECD. (2002). OECD best practices for budget transparency. OECD.

13. Rahmatika, D. N. (2014). The impact of internal audit function effectiveness on quality of financial reporting and its implications on good government governance research on local government Indonesia. Research Journal of Finance and Accounting, 5(18), 64-75.

14. Sabatier, P. A. (1986). Top-down and bottom-up approaches to implementation research: a critical analysis and suggested synthesis. Journal of Public Policy, 2148.

15. Santiso, C., \& Belgrano, A. G. (2004). Legislative Budget Oversight and Public Finance Accountability in Presidential Systems: Governance of the Budget in Peru. Paper prepared for the XVI Regional Seminar on Fiscal Policy of ECLAC (UN Economic Commission for Latin America and the Caribbean), Santiago de Chile, 26-29 January.

16. Stair-Hall, G. (2011). Legislative oversight: A guidebook for Ohio legislators. Ohio Legislative Service Commission.

17. Sukmadilaga, C., Pratama, A., \& Mulyani, S. (2015). Good governance implementation in the public sector: Exploratory analysis of government financial statements disclosures across ASEAN Countries. Procedia-Social and Behavioral Sciences, 211, 513-518.

18. The 1945 Constitution of the Republic of Indonesia and Article 15 of Law Number 17 of 2003 concerning State Finances. 